\title{
Synthesis and anti-fungal effect of silver nanoparticles-chitosan composite particles
}

\author{
This article was published in the following Dove Press journal: \\ International Journal of Nanomedicine \\ I April 2015 \\ Number of times this article has been viewed
}

\section{Lung-Shuo Wang ${ }^{1-4}$ \\ Chih-Yu Wang ${ }^{2}$ \\ Chih-Hui Yang ${ }^{5}$ \\ Chen-Ling Hsieh ${ }^{3,5}$ \\ Szu-Yu Chen ${ }^{3,5}$ \\ Chi-Yen Shen' \\ Jia-Jung Wang ${ }^{2}$ \\ Keng-Shiang Huang ${ }^{3}$}

'Department of Electrical Engineering,

I-Shou University, Kaohsiung,

Taiwan; ${ }^{2}$ Department of Biomedical

Engineering, I-Shou University,

Kaohsiung, Taiwan; ${ }^{3}$ The School

of Chinese Medicine for Post-

Baccalaureate, I-Shou University,

Kaohsiung, Taiwan; ${ }^{4}$ Department

of Chinese Medicine, E-Da Hospital,

Kaohsiung, Taiwan; ${ }^{5}$ Department

of Biological Science and Technology,

I-Shou University, Kaohsiung, Taiwan

Correspondence: Jia-Jung Wang

Department of Biomedical Engineering,

I-Shou University, No 8 Yida Road,

Jiaosu Village, Yanchao District,

Kaohsiung City 82445,Taiwan

Email wangjj@isu.edu.tw

Keng-Shiang Huang

The School of Chinese Medicine for Post-Baccalaureate, I-Shou University,

No 8 Yida Road, Jiaosu Village, Yanchao

District, Kaohsiung City 82445, Taiwan

Email huangks@is.edu.tw

\begin{abstract}
Silver nanoparticles have been used in various fields, and several synthesis processes have been developed. The stability and dispersion of the synthesized nanoparticles is vital. The present article describes a novel approach for one-step synthesis of silver nanoparticlesembedded chitosan particles. The proposed approach was applied to simultaneously obtain and stabilize silver nanoparticles in a chitosan polymer matrix in-situ. The diameter of the synthesized chitosan composite particles ranged from $1.7 \mathrm{~mm}$ to $2.5 \mathrm{~mm}$, and the embedded silver nanoparticles were measured to be $15 \pm 3.3 \mathrm{~nm}$. Further, the analyses of ultraviolet-visible spectroscopy, energy dispersive spectroscopy, and X-ray diffraction were employed to characterize the prepared composites. The results show that the silver nanoparticles were distributed over the surface and interior of the chitosan spheres. The fabricated spheres had macroporous property, and could be used for many applications such as fungicidal agents in the future.
\end{abstract}

Keywords: silver, nanoparticles, chitosan, anti-fungal

\section{Introduction}

Silver nanoparticles exhibit many unique electronic, catalytic, optical, and other physical and chemical properties that their bulk counterparts do not have. ${ }^{1}$ Silver nanoparticles have been applied in many fields including photonics, micro-electronics, photocatalysis, lithography, and surface-enhanced Raman spectroscopy., ${ }^{2,3}$ Several types of chemical and physical technologies, such as chemical reduction, ${ }^{4-6}$ electrochemical reduction, ${ }^{7-9}$ photochemical reduction, ${ }^{10-12}$ and heat evaporation ${ }^{13,14}$ have been developed for the synthesis of silver nanoparticles. In recent years, bio- or green-synthesis of silver nanoparticles has become an emerging science. For example, using plant extracts for reducing silver nitrite to obtain nanoparticles with antimicrobial activities has emerged as a cost-effective and eco-friendly approach. ${ }^{15,16}$

The fabrication of silver nanoparticles has been widely studied, and their stability and dispersion are crucial. Stabilizers such as surfactants, micelles, ligands, and polymers have been widely utilized in the literature. ${ }^{17-20}$ Recently, incorporating metal nanoparticles into polymers has been proposed. Immobilizing metal nanoparticles on matrix polymers called nanometal polymer hybrids efficiently prevents nanoparticles' aggregation. ${ }^{21}$ In addition, the biocompatibility can thus be improved. ${ }^{22}$ Polymers can act as matrix materials to help metal nanoparticles' growth control and stabilization. ${ }^{23}$ Various polymers have been employed for the synthesis of silver nanoparticles-polymer composites. ${ }^{24}$ In addition, polymers [eg, chitosan, gelatin, ${ }^{25-27}$ liposome, ${ }^{28}$ poly(lactic acid), ${ }^{29}$ polymethylmethacrylate, ${ }^{30}$ poly(vinyl alcohol), ${ }^{31}$ polyvinylpyrrolidone, ${ }^{32,33}$ etc] can be used as reducing or stabilizing agents for the synthesis of silver nanoparticles, without other reducing agents. ${ }^{34,35}$ For example, Bankura et al proposed a simple onestep synthesis of silver nanoparticles exhibiting multiple antimicrobial activities with 
size range of $10-60 \mathrm{~nm}$ by reduction of silver nitrate $\left(\mathrm{AgNO}_{3}\right)$ using aqueous dextran solution as both reducing and capping agent. ${ }^{36}$ Recently, several strategies for silver nanoparticles polymer hybrids were proposed. For example, El-Rafie et al developed a green synthesis process for silver nanoparticles' generation by using polysaccharides extracted from marine macroalgae. ${ }^{37}$ Wang et al fabricated uniform polystyrene spheres coated with silver nanoparticles by simultaneous photo-induced polymerization and reduction. ${ }^{38}$ AbdelMohsen et al synthesized core-shell structures of silver/ chitosan- $O$-methoxy polyethylene glycol nanoparticles. ${ }^{39}$

Spherical solid supports for silver nanoparticles such as microspheres are crucial for several fungicidal applications. For example, silver nanoparticles-embedded methacrylic acid copolymer microspheres were found to be effective bactericidal agents for water sterilization, because they were quite stable and were not washed away by water. ${ }^{40}$ In addition, some hybrid materials with embedded silver nanoparticles were used against Candida spp., Escherichia coli, Pseudomonas sp., Aspergillus niger or Penicillium sp., and others. ${ }^{40-44}$ In order to apply the silver nanoparticles composite materials to industry, developing a facile and low cost method for the synthesis of silver nanoparticles polymer composite particles becomes vital.

In this study, we would like to present a facile approach to produce uniform silver nanoparticles-chitosan composite spheres, and test the fungicidal properties of the prepared hybrid spheres. The fabricated spheres would be characterized by UV-Vis spectroscopy, Fourier transform infrared spectroscopy (FTIR), scanning electron microscopy (SEM), transmission electron microscopy (TEM), and energy dispersive spectroscopy (EDS).

\section{Materials and methods \\ Materials}

Chitosan (molecular weight: 150,000, 1.5\% w/v), $\mathrm{AgNO}_{3}$, glucose, and sodium hydroxide $(\mathrm{NaOH})$ were purchased from Sigma-Aldrich Co. (St Louis, MO, USA), and used as received without further purification.

\section{Synthesis of the chitosan spheres}

Chitosan $(0.2 \mathrm{~g}$, dissolved in $10 \mathrm{~mL}$ of $1 \% \mathrm{v} / \mathrm{v}$ acetic acid $\left[\mathrm{CH}_{3} \mathrm{COOH}\right]$ solution) was prepared and dropped into a $20 \%$ $25 \mathrm{~mL} \mathrm{NaOH}$ solution using syringes $\left(3 \mathrm{~mL}\right.$, Terumo $\left.{ }^{\circledR}\right)$ with 24 gauge needle $\left(24 \mathrm{G} \times 1^{\prime \prime}\right.$, Terumo $\left.{ }^{\circledR}\right)$ and a pump. Chitosan spheres were obtained after 15 minutes. Spheres were collected and washed twice with $30 \mathrm{~mL}$ of dd- $\mathrm{H}_{2} \mathrm{O}$ (double distilled water) to remove residual alkali.

\section{Synthesis of the Ag nanoparticles- chitosan composite spheres}

Based on our previous studies, ${ }^{41-44}$ the one-step production of silver nanoparticles-chitosan composite spheres is shown in Figure 1. Chitosan $(0.2 \mathrm{~g}$, dissolved in $10 \mathrm{~mL}$ of $1 \% \mathrm{v} / \mathrm{v}$ $\mathrm{CH}_{3} \mathrm{COOH}$ solution) and $2 \% 10 \mathrm{~mL} \mathrm{AgNO}_{3}$ was mixed by constant stirring for 30 minutes, and then an $\mathrm{AgNO}_{3}$-chitosan mixture solution was obtained. The $\mathrm{AgNO}_{3}$-chitosan mixture solution was then dropped into a $20 \%, 30 \%$, or $40 \%$, $25 \mathrm{~mL} \mathrm{NaOH}$ solution, respectively by using a syringe pump. After 15 minutes, yellow-brown color spheres (eg, silver nanoparticles-chitosan composite spheres) were yielded. Spheres were collected and washed twice with $30 \mathrm{~mL}$ of dd $-\mathrm{H}_{2} \mathrm{O}$ to remove residual alkali.

\section{Characterization}

The average diameter of the spheres, expressed as mean \pm standard deviation, was obtained from the photographs taken by random sampling of approximately 50 individual particles to minimize selection bias. X-ray diffraction (XRD, D8 Advance, PANalytical X'PERT PRO) patterns were obtained at room temperature using $\mathrm{Cu} \mathrm{K}-\alpha$ radiation $(\lambda=1.5406 \AA)$ with a range of $2 \theta=20^{\circ}$ to $80^{\circ}$, and a scanning rate of $0.05 \mathrm{~s}^{-1}$. The FTIR spectra were recorded with a Spectrum RXI FTIR Spectrometer, using $\mathrm{KBr}$ pellets, in the range of 400 to $4,000 \mathrm{~cm}^{-1}$, with a resolution of $4 \mathrm{~cm}^{-1}$. The micromorphology of the silver nanoparticles-chitosan composite spheres was analyzed using a SEM (S-2700, Hitachi Ltd., Tolyo, Japan) equipped with an energy dispersive spectrometer. The characterization of the silver nanoparticles was carried out using TEM (FEI Tecnai $\mathrm{G}^{2} 20 \mathrm{~S}$-Twin) and a UV-Vis absorbance spectrophotometer (Thermo Scientific Spectrascan UV 2700). The silver nanoparticles solution was prepared by adding $20 \mu \mathrm{L} \mathrm{CH}_{3} \mathrm{COOH}$ solution and $1 \mathrm{~mL}$ dd- $\mathrm{H}_{2} \mathrm{O}$ to ten silver nanoparticles-chitosan composite spheres, and then vortexing for 3-5 minutes. The silver nanoparticles-chitosan solution was dropped to grid by a micropipette for TEM analysis report.

\section{Anti-fungal effect test of Cordyceps militaris or Antrodia cinnamomea}

To test anti-fungal effect, we used C. militaris (or Cm, Bioresource Collection and Research Center (BCRC) 32219) or $A$. cinnamomea (or Ac, BCRC 35716) in this study. We spread $\mathrm{Cm}$ or Ac on BCRC agar plate (malt Extract 2\%, BD 218630; peptone $0.1 \%$, BD 211677; glucose 2\%, J.T.Baker 1916-05; agarose $1.5 \%$ ) until these plates were fully covered by them. The silver nanoparticles-chitosan solution was prepared by adding $20 \mu \mathrm{L} \mathrm{CH}_{3} \mathrm{COOH}$ solution and $1 \mathrm{~mL}$ dd- $\mathrm{H}_{2} \mathrm{O}$ to ten 


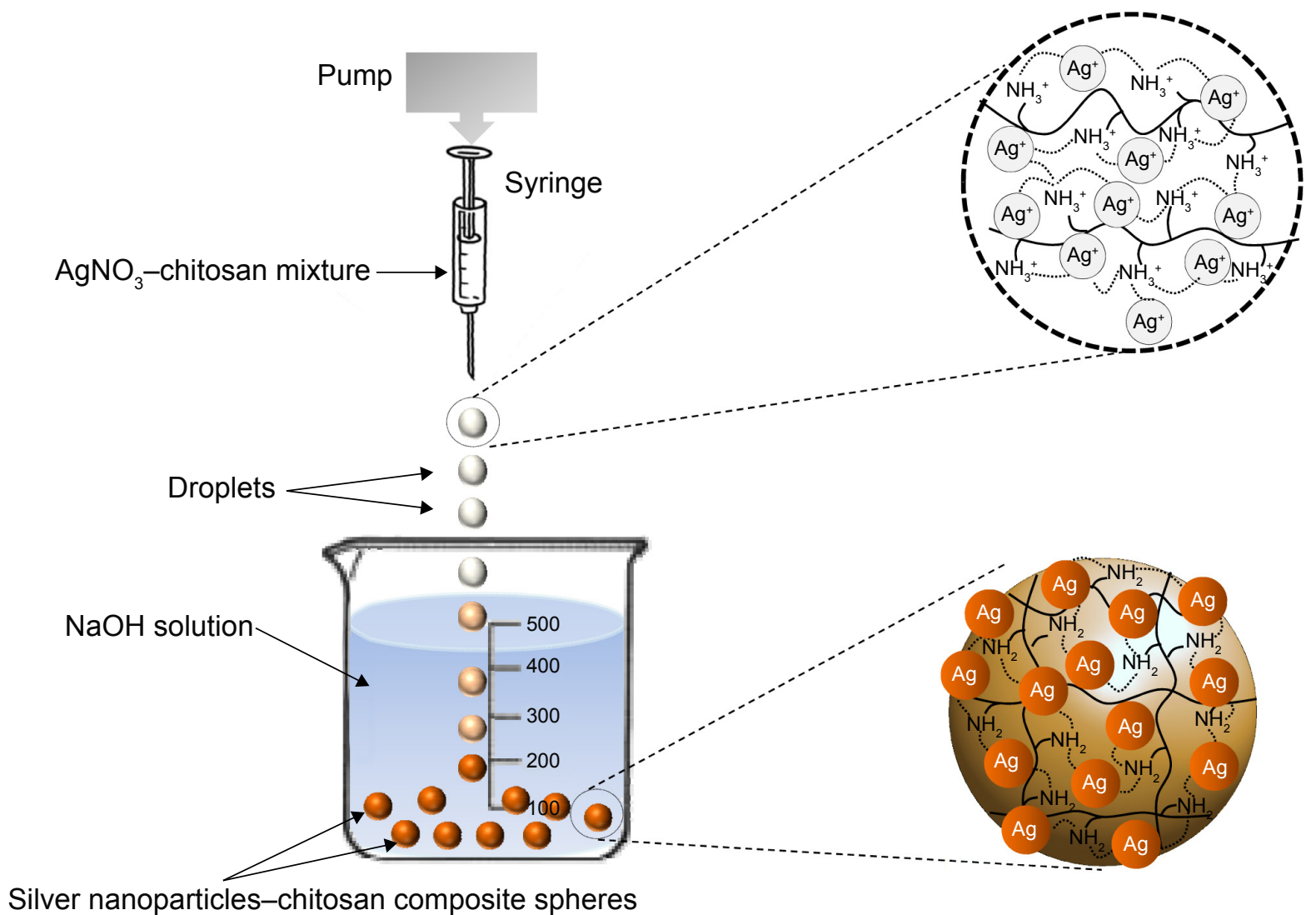

Figure I Schematic drawing of the silver nanoparticles-chitosan composite spheres synthesis.

Notes: Droplets were pushed out from pin tip of a pump-driven syringe and then dropped into an $\mathrm{NaOH}$ solution, which was used for silver nanoparticles' reduction and chitosan solidification. Silver nanoparticles-chitosan composite spheres were formed in 15 minutes. The distance between solidifying liquid surface and the tip was one centimeter. The diameter of the needle of the syringe was $8.73 \mathrm{~mm}$.

Abbreviations: $\mathrm{AgNO}_{3}$, silver nitrate; $\mathrm{NaOH}$, sodium hydroxide.

silver nanoparticles-chitosan composite spheres, and then vortex for 3-5 minutes. The chitosan solution was prepared by adding $20 \mu \mathrm{L} \mathrm{CH}_{3} \mathrm{COOH}$ solution and $1 \mathrm{~mL}$ dd- $\mathrm{H}_{2} \mathrm{O}$ to ten chitosan spheres, and then vortexing for 3-5 minutes. Then we put a round filter paper (diameter $2 \mathrm{~cm}$ ) with dissolved chitosan sphere or silver nanocomposite chitosan sphere in the middle of the plate and calculated the diameters of the inhibition zone on Day 0, Day 9, and Day 18, respectively. The analysis graph was drawn by GraphPad Prism and data were analyzed using the two-way analysis of variance (ANOVA). A $P$-value less than 0.05 was considered statistically significant.

\section{Results and discussion Morphology of silver nanoparticles- chitosan composite spheres}

Figure 2 shows that the silver nanoparticles-chitosan composite spheres are obtained by using various concentrations of $\mathrm{AgNO}_{3}$. The pure chitosan spheres showed milky-white (Figure 2A), whereas the fabricated spheres showed more gray when the concentration of $\mathrm{AgNO}_{3}$ (Figure 2B) was lower, and more khaki when the concentration of $\mathrm{AgNO}_{3}$ was higher (Figure 2C). The color variation provided some clues to the formation of silver nanoparticles. ${ }^{45}$ Highly coherent appearance of the prepared silver nanoparticles-chitosan composite spheres was obtained when various concentrations of $\mathrm{AgNO}_{3}$ were used. However, the diameter of the silver nanoparticles seemed to decrease with an increasing concentration of $\mathrm{AgNO}_{3}$ (Table 1). Most of the relative standard deviations of the sphere diameters observed at various concentrations of $\mathrm{AgNO}_{3}$ were less than $10 \%$, indicating that the manufactured spheres met the typical criterion for monodispersity ${ }^{46}$ Results shown in Figure 2 illustrate the composite spheres fabricated with low concentrations of $\mathrm{AgNO}_{3}$ were slightly flattened in contact with the plate bottom, and thus they became slightly enlarged when measured by a top view. This phenomenon occurred because of fewer silver nanoparticles decreasing the mechanical strength of the spheres. In contrast, when the composite spheres were fabricated with high concentrations of $\mathrm{AgNO}_{3}$ (there will be more silver nanoparticles formed), the composite spheres 

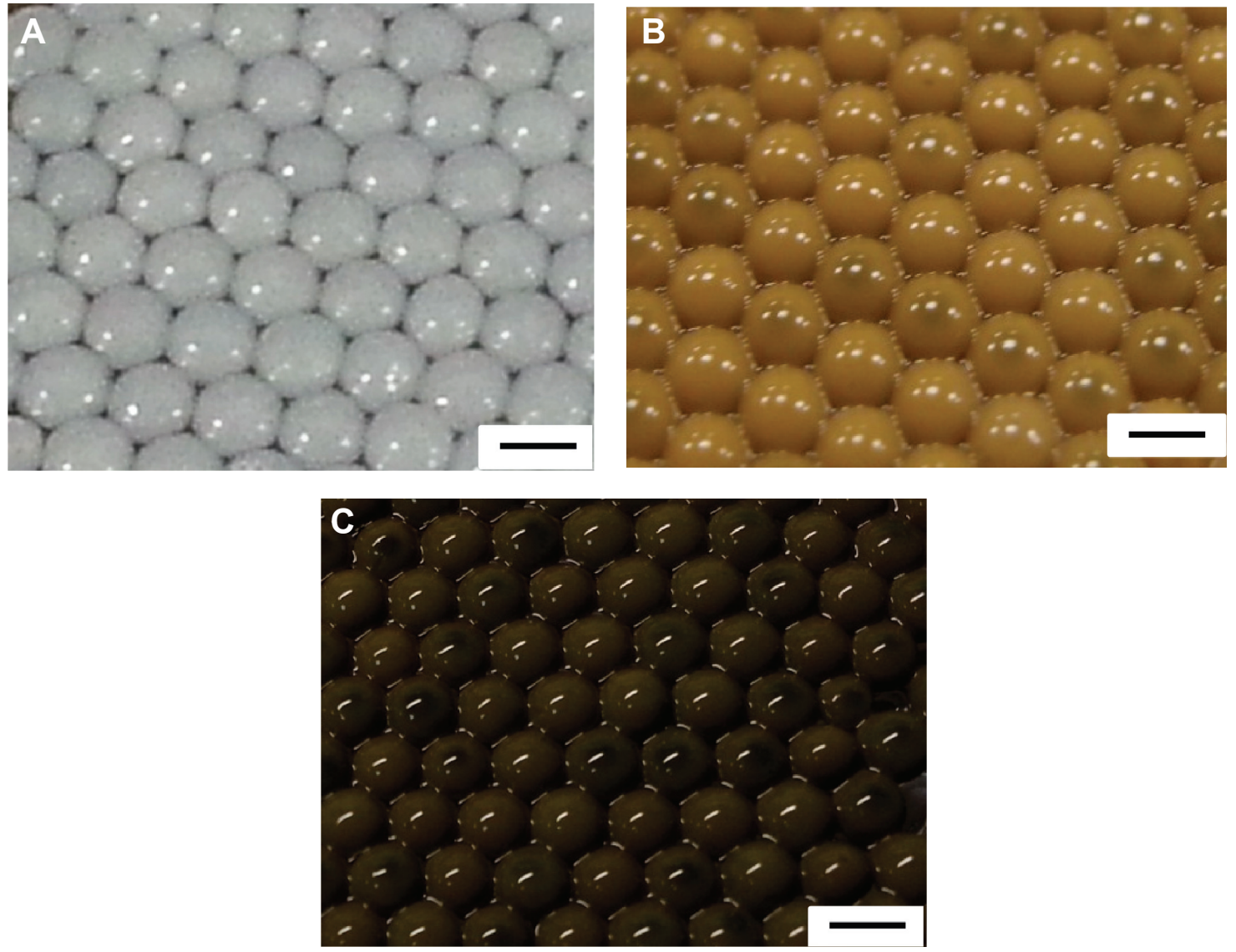

Figure 2 Photographs of the synthesized spheres.

Notes: (A) Chitosan spheres. (B) Silver nanoparticles-chitosan composite spheres synthesized with I mM AgNO . (C) Silver nanoparticles-chitosan composite spheres synthesized with $8 \mathrm{mM} \mathrm{AgNO}$. The concentration of chitosan was $2 \%$. All scale bars are $2 \mathrm{~mm}$.

Abbreviation: $\mathrm{AgNO}_{3}$, silver nitrate.

presented a superior mechanical strength, and thus exhibited properties such as easy spheroidization and aversion to deformation and fragmentation. The literature related to the fabrication of silver nanoparticles-chitosan composite films has mentioned that silver nanoparticles were uniformly dispersed and captured by the networks of amine $\left(-\mathrm{NH}_{2}\right)$ and hydroxyl (-OH) functional groups, ${ }^{47}$ and thus the mechanical strength could be enhanced. ${ }^{48,49}$ Those results were consistent

Table I The relationship between average diameter of fabricated silver-chitosan composite spheres and the concentration of silver nitrate $\left(\mathrm{AgNO}_{3}\right)$

\begin{tabular}{|c|c|c|c|}
\hline $\begin{array}{l}\mathrm{AgNO}_{3} \text { concentration } \\
(\mathrm{mM})\end{array}$ & $\begin{array}{l}\text { Sphere diameter } \\
(\mathrm{mm})\end{array}$ & SD (mm) & RSD (\%) \\
\hline 0.25 & 2.10 & 0.13 & 6.21 \\
\hline 0.5 & 2.48 & 0.18 & 7.28 \\
\hline 1 & 1.97 & 0.24 & 12.02 \\
\hline 2 & 1.66 & 0.18 & 10.6 \\
\hline 4 & 1.79 & 0.18 & 9.8 \\
\hline 8 & 1.76 & 0.14 & 8.14 \\
\hline
\end{tabular}

Abbreviations: SD, standard deviation; RSD, relative standard deviation. with our finding. We presume that the silver nanoparticles in silver nanoparticles-polymer composite play an identical role of cramp bar in architecture to reinforced concrete. Concrete (imagine as polymer) has relatively low tensile strength, while the presence of reinforcing bars (imagine as silver nanoparticles) shows higher tensile strength and/or ductility.

\section{Characterization of silver nanoparticles- chitosan composite spheres}

Figure 3 shows the UV-Vis absorbance spectra of the synthesized silver nanoparticles-chitosan composite spheres at various concentrations of $\mathrm{NaOH}$. Two significant peaks were observed: the peak at $275 \mathrm{~nm}$ is a characteristic peak of chitosan, whereas $410 \mathrm{~nm}$ is a characteristic peak of nano size silver particles. ${ }^{50}$ Figure $\mathrm{S} 1$ shows the TEM photo of the synthesized silver nanoparticles. The particle size was measured to be $15 \pm 3.3 \mathrm{~nm}$, which was consistent with the result of UV-Vis spectroscopy. The absorption peaks of the UV-V is spectra shifted to a longer wavelength when the particle 


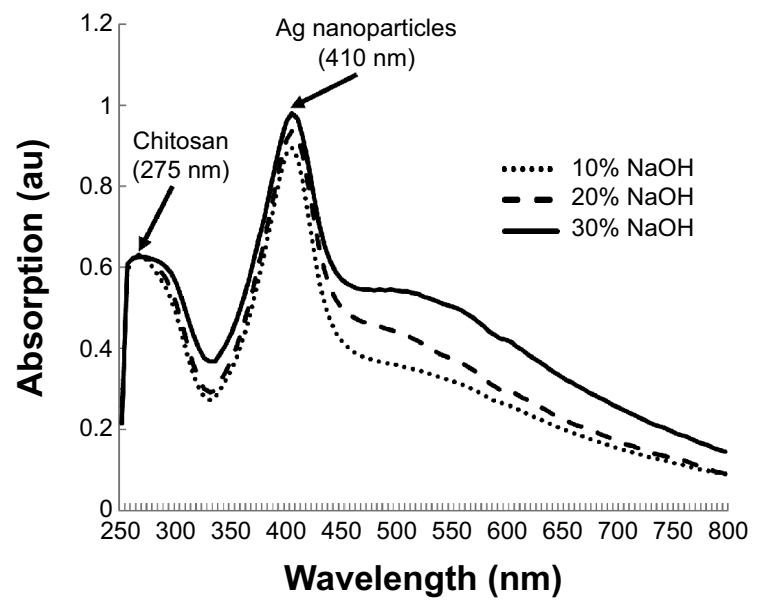

Figure 3 The UV-Vis absorbance spectra of the synthesized silver-chitosan composite spheres at various concentrations of $\mathrm{AgNO}_{3}$ solution.

Abbreviations: $\mathrm{AgNO}_{3}$, silver nitrate; $\mathrm{NaOH}$, sodium hydroxide; au, arbitrary unit; UV-Vis, ultraviolet-visible spectroscopy.

diameters were increased.$^{50}$ Nevertheless, the results shown in Figure 3 presume that there is nearly no change in the peaks $(\sim 410 \mathrm{~nm})$ at the various concentrations of $\mathrm{NaOH}$, indicating that the concentration of $\mathrm{NaOH}$ has no significant influence on the diameters of the synthesized silver particles.

Figure 4A shows the FTIR spectra of the silver nanoparticles-chitosan composite spheres. The bands between $3,462 \mathrm{~cm}^{-1}$ and $3,441 \mathrm{~cm}^{-1}$ were related to the stretching vibrations of amino groups from $\mathrm{NH}$-amine. The bands between $2,925 \mathrm{~cm}^{-1}$ and $2,891 \mathrm{~cm}^{-1}$ corresponded to the alkane $\mathrm{C}$-H-stretching lipids. The bands between $1,632 \mathrm{~cm}^{-1}$ and $1,597 \mathrm{~cm}^{-1}$ corresponded to the amino groups of amide. The bands between $1,385 \mathrm{~cm}^{-1}$ and $1,387 \mathrm{~cm}^{-1}$ were associated with the $\mathrm{C}=\mathrm{C}$ stretching of aromatic amine groups. The bands between $1,077 \mathrm{~cm}^{-1}$ and $1,075 \mathrm{~cm}^{-1}$ were related to the carbonyl stretch in proteins. The silver nanoparticles were bonded by protein, which served as a stabilizing agent, either through free amine groups or cysteine residues..$^{51,52}$ These proteins were present as enzymes that could reduce $\mathrm{AgNO}_{3}$ ions to form silver nanoparticles. ${ }^{52}$

Figure 4B shows the XRD patterns of the silver nanoparticles-chitosan composite spheres. Four characteristic peaks of silver nanoparticles corresponding to (111), (200), (220) and (311) are consistent with those found in the Joint Committee on Powder Diffraction Standards (JCPDS) database (PDF No. 65-3107). The results show that the synthesized nanoparticles were silver nanoparticles, because the position and relative intensity of all the diffraction peaks of the samples were consistent with the crystalline pattern of silver. ${ }^{53}$ Furthermore, the chitosan being used for the synthesis process did not cause the formation of silver oxides. The shape of each peak was broadened as a result of the presence of the chitosan polymer. ${ }^{54}$ Line broadening in the pattern was quantitatively evaluated by using the Debye-Scherrer equation $\mathrm{d}=(\mathrm{k} \lambda / \beta \cos \theta)$, which showed the relationship between peak broadening in the XRD and particle size. ${ }^{55}$

Figure 5 shows the SEM photographs of the fabricated silver nanoparticles-chitosan composite spheres (using $1 \mathrm{mM}$ $\mathrm{AgNO}_{3}$ and $20 \% \mathrm{NaOH}$ ). Figure $5 \mathrm{~A}-\mathrm{C}$ shows the SEM graphs of the surface and the "zoom-in" of their intact sphere counterparts. Figure 5D-F represent the SEM graphs of the morphology, and the "zoom-in" of their sectional sphere counterparts. The results show that the spheres possessed many irregular macro pores, particularly in their interior. Figure S2 shows the morphology of the chitosan spheres, which have relatively smooth structures compared with the silver nanoparticles-chitosan composite spheres. Vimala et al
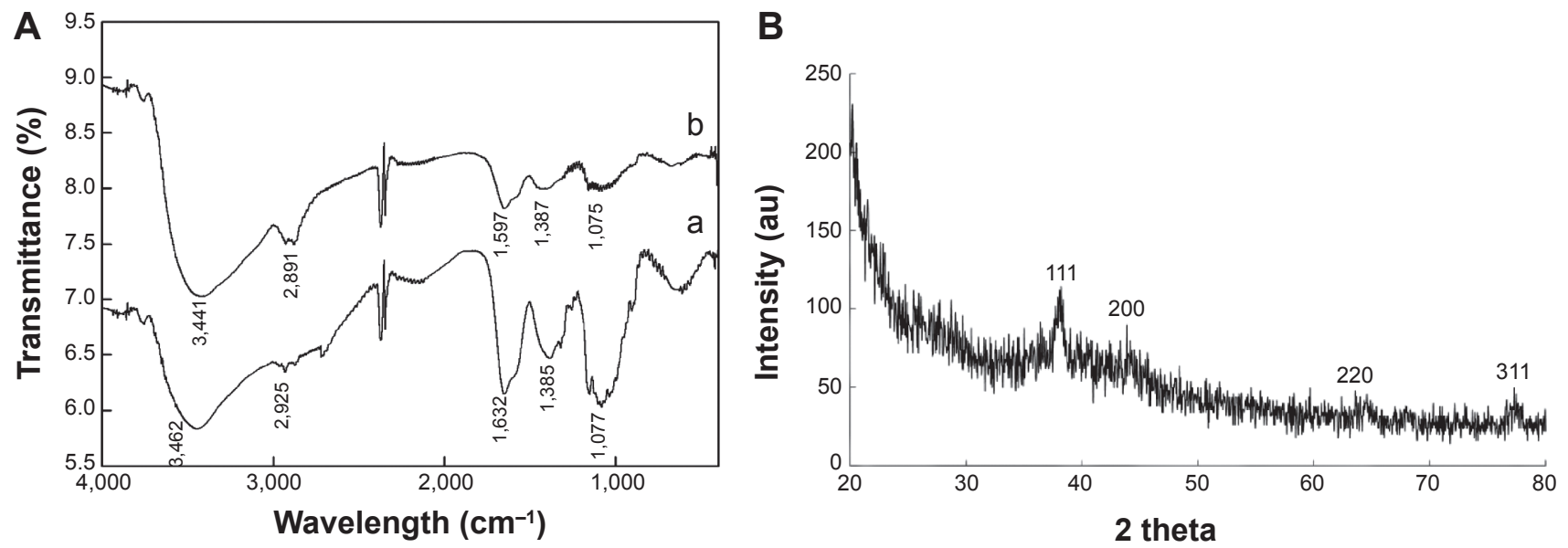

Figure 4 Characterization of silver nanoparticles-chitosan composite spheres by FTIR and XRD.

Notes: (A) The FTIR spectrum, a represents Ag@chitosan, b represents chitosan and (B) the XRD graphs of the fabricated silver nanoparticles-chitosan composite spheres. Abbreviations: FTIR, Fourier transform infrared spectroscopy; XRD, X-ray diffraction; au, arbitrary unit. 

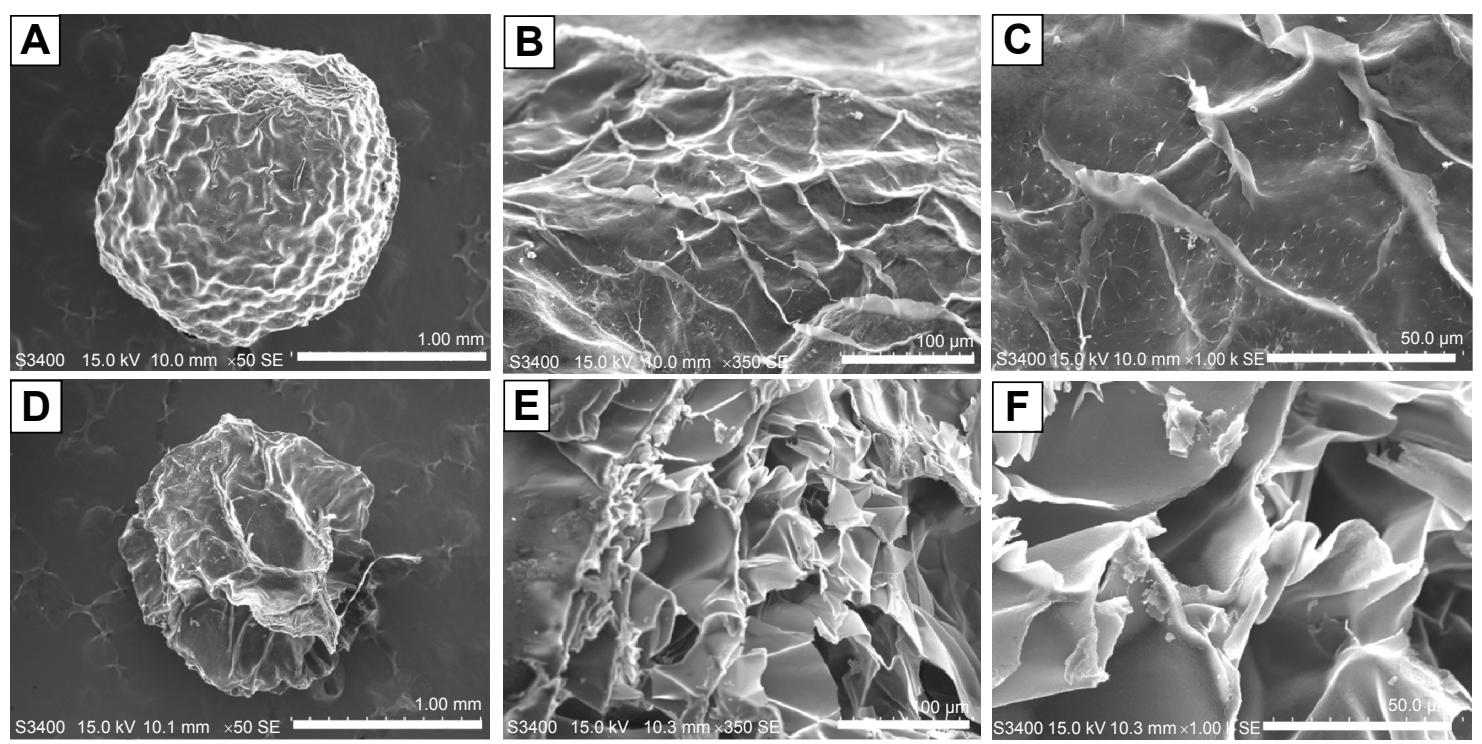

Figure 5 The SEM photographs of the synthesized silver nanoparticles-chitosan composite spheres.

Notes: Panel (A) is the SEM photograph of a whole sphere. Panels (B) and (C) are the "zoom-in" counterparts of (A). Panel (D) is the SEM photograph of a sectioned sphere. Panels (E) and (F) are the "zoom-in" counterparts of (D). The scale bars are I mm (A and D), $100 \mu \mathrm{m}(\mathbf{B}$ and $\mathbf{E})$, and $50 \mu \mathrm{m}(\mathbf{C}$ and $\mathbf{F})$, respectively.

Abbreviation: SEM, scanning electron microscopy.

synthesized porous chitosan-silver nanocomposite films that had interdisciplinary applications in wound dressing, antibacterial agents, and water purification. ${ }^{49}$ In our study, the silver nanoparticles-chitosan composite spheres also possessed porous structures, and could be used in multiple fields.

Figure S3 shows the EDS of the silver nanoparticles deposited on the outer surface relative to Figure $5 \mathrm{~A}, \mathrm{~B}, \mathrm{C}$ (Figure S3A), as well as the EDS of the inside of the synthesized silver nanoparticles-chitosan composite spheres relative to Figure 5D, E, F (Figure S3B). The intensity of the silver signal of the outer surface was higher than that inside the spheres, indicating that more silver nanoparticles were embedded in the interior of the spheres than deposited on the outer surface. The SEM-EDS mapping images presented in Figures $\mathrm{S} 3 \mathrm{C}$ and D show the silver nanoparticles deposited on the outer surface and interior of the synthesized silver nanoparticles-chitosan composite spheres, respectively. The green dots represent the elemental map of the silver nanoparticles, which were considerably less on the outer surface than inside the spheres. The results of Figure S3C and D were consistent with those in Figure S3A and B.

\section{Anti-fungal effect test of silver nanoparticles-chitosan composite spheres}

Figure 6 shows the anti-fungal effect. We found that $\mathrm{Cm}$ is inhibited by dissolved chitosan and silver nanoparticleschitosan composite spheres (Ag@chitosan) on Day 9 (the inhibition ring diameter of chitosan is $3.2 \pm 0.1 \mathrm{~cm}$ and $\mathrm{Ag} @$, chitosan is $3.533 \pm 0.217 \mathrm{~cm}$ ) and Day 18 (the inhibition ring diameter of chitosan is $2.7 \pm 0.2 \mathrm{~cm}$ and $\mathrm{Ag} @$ chitosan is $3.2 \pm 0.058 \mathrm{~cm}$ ) but not Ac. This finding indicates that $\mathrm{Ag} @$ chitosan and chitosan can both inhibit the growth of $\mathrm{Cm}$ but the activity of $\mathrm{Ag} @$ chitosan is better than chitosan (on Day 9, $P<0.05$; on Day $18, P<0.01$ ). It is interesting to note that no inhibition ring is formed in Ac group, indicating that Ac is not affected by Ag@chitosan and chitosan. It is worth mentioning that on Day 9 we found not only chitosan but also $\mathrm{Ag} @$ chitosan show the best anti-fungal effects. We speculate that the reduction of anti-fungal effect might be caused by the degradation of chitosan and Ag@chitosan. As widely known, both chitosan and $\mathrm{Ag} @$ chitosan can inhibit many kinds of microorganisms. In this study, we found that $\mathrm{Ag} @$ chitosan or chitosan can inhibit the growth of $\mathrm{Cm}$ but not Ac. Taken all together, we thought chitosan and Ag@chistosan can act as a potent reagent to enhance Ac production by inhibiting other microorganism growth.

Bacterial infections still remain a major issue within health care industry and medical research. Therefore, it is urgently needed to develop novel antibiotics with high biocompatibility and without limitations of drug-resistance. Among diverse investigated antimicrobial agents, silver is one of the most promising because of its intrinsic properties of high thermal stability, low toxicity to mammalian cells and tissues, ${ }^{56,57}$ versatile and long-term activity. ${ }^{58}$ Synthesis of silver nanoparticles or silver-based antimicrobial 
A 1. $\mathrm{Cm}$ and $\mathrm{Ac}$ were spread on $\mathrm{BCRC}$ agar plate respectively.
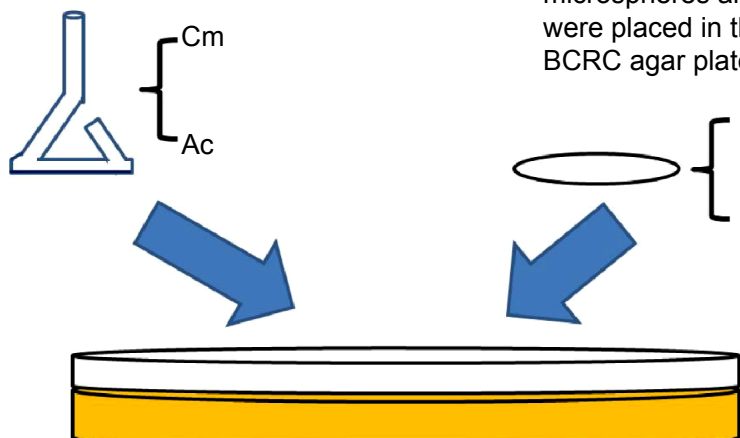

\section{B Day 0}

Control

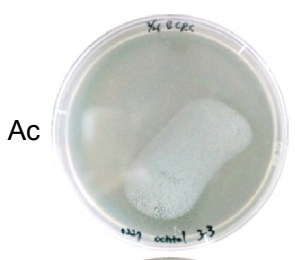

$x \in \mathrm{Cr}$

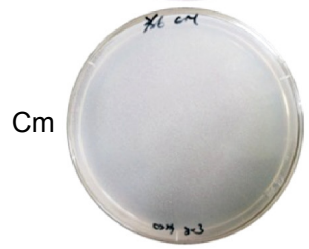

Day 9
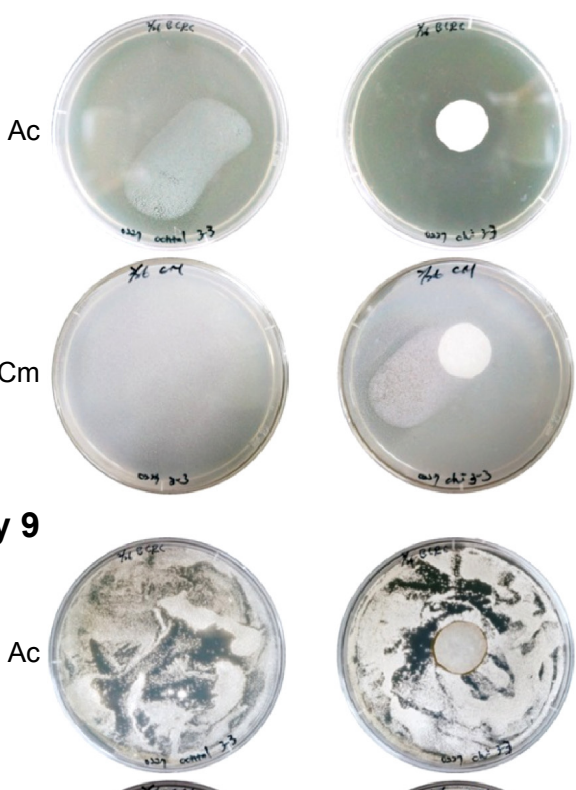

with dissolved chitosan

microspheres and Ag@chitosan

were placed in the middle of

$\mathrm{BCRC}$ agar plate respectively.
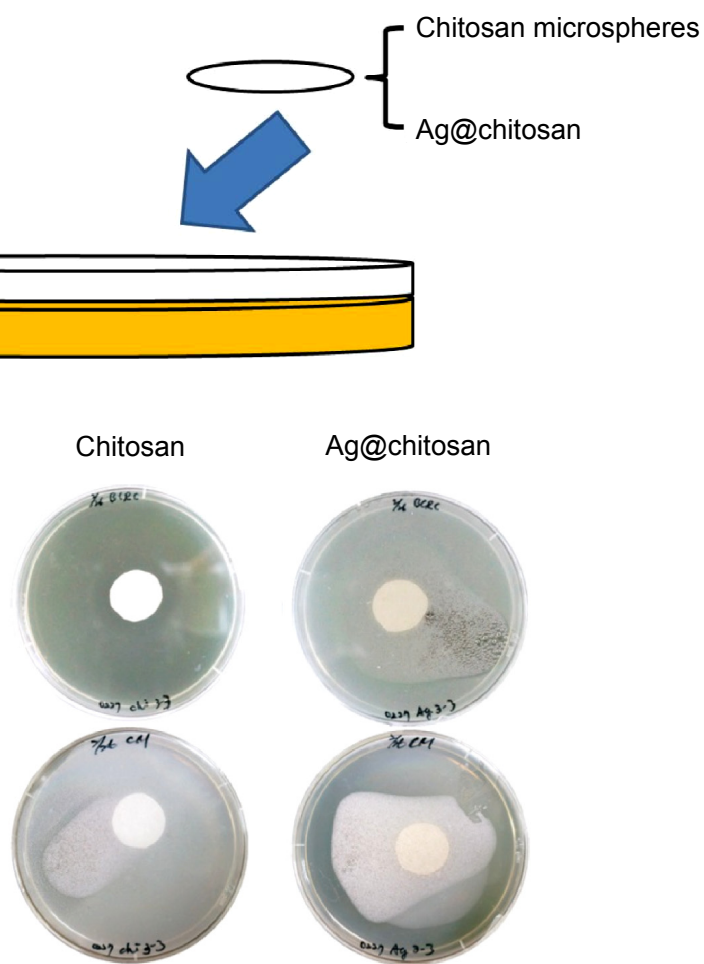

Ag@chitosan

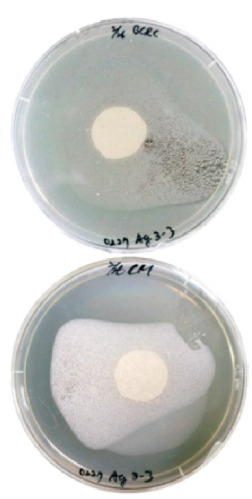

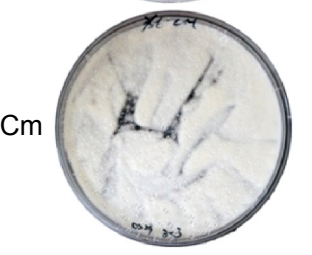

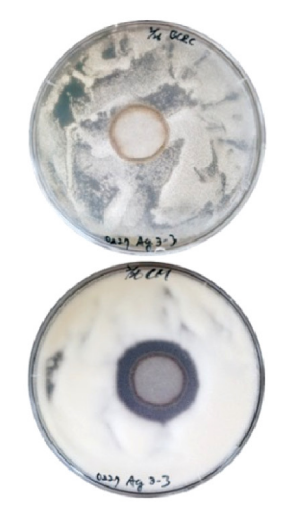

Day 18
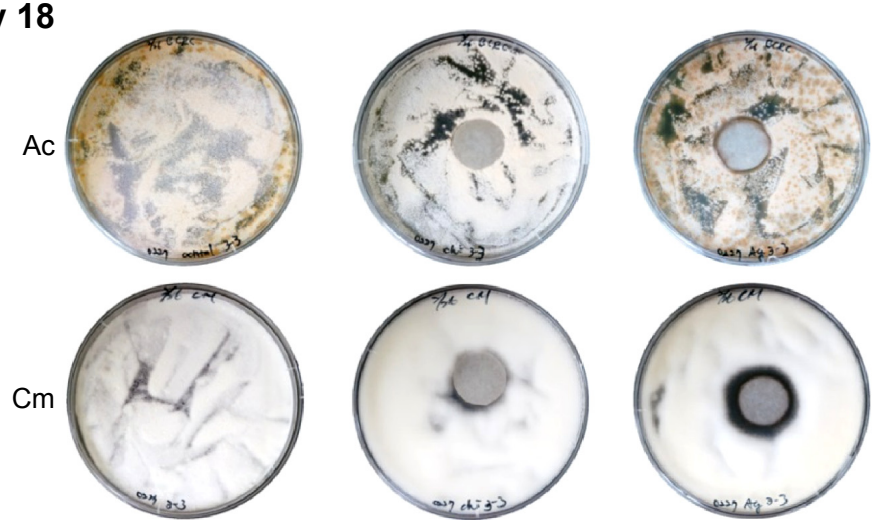

Figure 6 (Continued) 


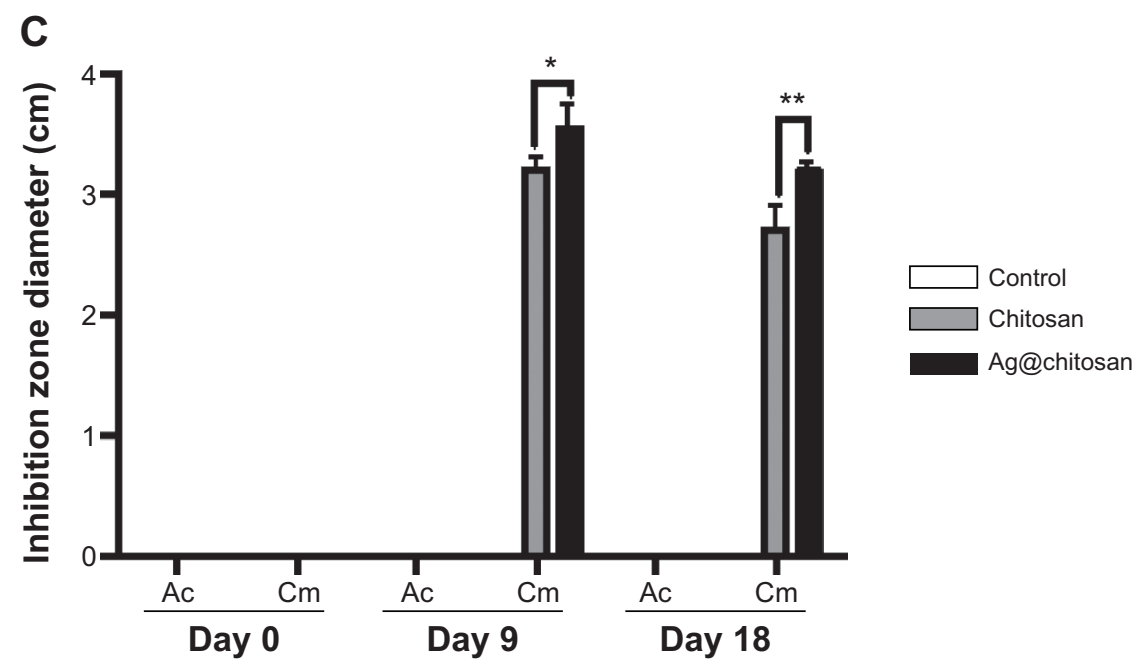

Figure 6 Ag@chitosan anti-fungal effect.

Notes: (A) Flow chart of silver nanoparticles' anti-fungal effect. (B) and $(\mathbf{C})$ the anti-fungal effect of chitosan microspheres and $\mathrm{Ag} @$ chitosan. $* P<0.05$, $* * P<0.0 \mathrm{I}$. Abbreviations: Ag@chitosan, silver nanoparticles-chitosan composite spheres; Cm, C. militaris; Ac, A. cinnamomea; BCRC, Bioresource Collection and Research Center.

nanocomposite was well established by miscellaneous methods, for example employed $\mathrm{AgNO}_{3}$ as starting material to obtain silver nanoparticles by chemical reduction with some natural reductant (such as chitosan, dextran, sodium citrate, ascorbate and other reducing biomolecules like polypeptides, flavones, and alkaloids). ${ }^{59-61}$ A number of literatures have reported that silver nanoparticles incorporated with chitosan-based matrix present a broad spectrum of antimicrobial activity to inhibit both Gram-positive and Gram-negative bacteria including multidrug-resistant pathogens such as $P$. aeruginosa, ampicillin-resistant $E$. coli, erythromycin-resistant Streptococcus pyogenes, methicillinresistant $S$. aureus (MRSA) and vancomycin-resistant S. aureus (VRSA) ${ }^{62-69}$ However, the application of silver nanocomposite and chitosan as antifungal effect in $\mathrm{Cm}$ and Ac is rare. This study shows a selective inhibition by chitosan and silver nanoparticles-chitosan composite, suggesting that the cellular wall composition or modification of $\mathrm{Cm}$ and $\mathrm{Ac}$ is distinct. With the unveiling of antifungal ability of chitosan and silver nanoparticles-chitosan composite, it could offer an alternative to conventional antibiotics and a great opportunity to develop next-generation antibiotics.

\section{Conclusion}

We proposed a facile approach for manufacturing silver nanoparticles-chitosan composite spheres in a one-step process. The diameters of the fabricated spheres ranged from 1.5 to $2.5 \mathrm{~mm}$, but their particle size could be reduced by using droplet microfluidic technology. The successful formation of silver nanoparticles was evaluated using FTIR, XRD, and EDS mapping. The TEM image shows that the diameter of the fabricated silver nanoparticles was $15 \pm 3.3 \mathrm{~nm}$. The UV-Vis spectroscopy shows a characteristic peak at approximately $410 \mathrm{~nm}$, confirming the size of silver particle is within the nanoscale range. The peak wavelength does not substantially change even when various concentrations of $\mathrm{NaOH}$ are used. Compared with other approaches, the main advantages of this approach were: i) uniform-sized spheres could be continuously fabricated in a one step process, ii) silver nanoparticles could be obtained and stabilized simultaneously in a chitosan matrix, and iii) spherical shapes could have a wider range of applications compared with film structures. Because of the properties of silver nanoparticles, the synthesized spheres could become potential bactericidal agents for water disinfection, anti-pathogens, or surface plasma resonance enhancers. In addition, in this study we also found that chitosan and $\mathrm{Ag} @$ chitosan can inhibit the growth of $\mathrm{Cm}$ but not Ac, suggesting that chitosan and $\mathrm{Ag} @$ chitosan may be a potential reagent to enhance Ac production by preventing other microorganism growth.

\section{Acknowledgments}

This work was financially supported by a grant from the Ministry of Science and Technology, Taiwan, and Dr LungShuo Wang.

\section{Disclosure}

The authors have no conflicts of interest to disclose. 


\section{References}

1. Sun Y. Controlled synthesis of colloidal silver nanoparticles in organic solutions: empirical rules for nucleation engineering. Chem Soc Rev. 2013;42(7):2497-2511.

2. Bhui DK, Bar H, Sarkar P, Sahoo GP, De SP, Misra A. Synthesis and UV-vis spectroscopic study of silver nanoparticles in aqueous SDS solution. Journal of Molecular Liquids. 2009;145(1):33-37.

3. Stamplecoskie KG, Scaiano JC, Tiwari VS, Anis H. Optimal Size of Silver Nanoparticles for Surface-Enhanced Raman Spectroscopy. J Phys Chem C. 2011;115(5):1403-1409.

4. Khan Z, Al-Thabaiti SA, Obaid AY, Al-Youbi AO. Preparation and characterization of silver nanoparticles by chemical reduction method. Colloids Surf B Biointerfaces. 2011;82(2):513-517.

5. Wang H, Qiao X, Chen J, Ding S. Preparation of silver nanoparticles by chemical reduction method. Colloids and Surfaces A: Physicochemical and Engineering Aspects. 2005;256(2-3):111-115.

6. Dong X, Ji X, Wu H, Zhao L, Li J, Yang W. Shape Control of Silver Nanoparticles by Stepwise Citrate Reduction. J Phys Chem C. 2009; 113(16):6573-6576.

7. Roldán MV, Pellegri N, de Sanctis O. Electrochemical Method for Ag-PEG Nanoparticles Synthesis. Journal of Nanoparticles. 2013; 2013:1-7.

8. Tammeveski L, Erikson H, Sarapuu A, et al. Electrocatalytic oxygen reduction on silver nanoparticle/multi-walled carbon nanotube modified glassy carbon electrodes in alkaline solution. Electrochemistry Communications. 2012;20:15-18.

9. Zhang Y, Chen F, Zhuang J, et al. Synthesis of silver nanoparticles via electrochemical reduction on compact zeolite film modified electrodes. Chem Commun (Camb). 2002;(23):2814-2815.

10. Huang HH, Ni XP, Loy GL, et al. Photochemical Formation of Silver Nanoparticles in Poly(N-vinylpyrrolidone). Langmuir. 1996;12(4): 909-912.

11. Shen Z, Chen G, Chen Z, Qu X, Chen Y, Liu R, et al. Spatially selective photochemical reduction of silver on nanoembossed ferroelectric PZT nanowires. Langmuir. 2011;27(9):5167-5170.

12. Park H-H, Zhang X, Choi Y-J, Park H-H, Hill RH. Synthesis of Ag Nanostructures by Photochemical Reduction Using Citrate-Capped $\mathrm{Pt}$ Seeds. Journal of Nanomaterials. 2011;2011:1-7.

13. Smetana AB, Klabunde KJ, Sorensen CM. Synthesis of spherical silver nanoparticles by digestive ripening, stabilization with various agents, and their 3-D and 2-D superlattice formation. J Colloid Interface Sci. 2005;284(2):521-526.

14. Pyatenko A, Yamaguchi M, Suzuki M. Synthesis of Spherical Silver Nanoparticles with Controllable Sizes in Aqueous Solutions. J Phys Chem C. 2007;111(22):7910-7917.

15. Krishnaraj C, Jagan EG, Rajasekar S, Selvakumar P, Kalaichelvan PT, Mohan N. Synthesis of silver nanoparticles using Acalypha indica leaf extracts and its antibacterial activity against water borne pathogens. Colloids Surf B Biointerfaces. 2010;76(1):50-56.

16. Zargar M, Hamid AA, Bakar FA, et al. Green Synthesis and Antibacterial Effect of Silver Nanoparticles Using Vitex Negundo L. Molecules. 2011;16(8):6667-6676.

17. Ahmed MO, Leong WK. Colloidal silver nanoparticles stabilized by a water-soluble triosmium cluster. Journal of Organometallic Chemistry. 2006;691(5):1055-1060.

18. Baruah B, Gabriel GJ, Akbashev MJ, Booher ME. Facile synthesis of silver nanoparticles stabilized by cationic polynorbornenes and their catalytic activity in 4-nitrophenol reduction. Langmuir. 2013;29(13):4225-4234.

19. Pinto VV, Ferreira MJ, Silva R, et al. Long time effect on the stability of silver nanoparticles in aqueous medium: Effect of the synthesis and storage conditions. Colloids and Surfaces A: Physicochemical and Engineering Aspects. 2010;364(1-3):19-25.

20. Zou X, Bao H, Guo H, et al. Mercaptoethane sulfonate protected, water-soluble gold and silver nanoparticles: Syntheses, characterization and their building multilayer films with polyaniline via ion-dipole interactions. J Colloid Interface Sci. 2006;295(2):401-408.
21. Prozorova GF, Pozdnyakov AS, Kuznetsova NP, et al. Green synthesis of water-soluble nontoxic polymeric nanocomposites containing silver nanoparticles. Int J Nanomedicine. 2014;9:1883-1889.

22. Capadona JR, Van Den Berg O, Capadona LA, et al. A versatile approach for the processing of polymer nanocomposites with self-assembled nanofibre templates. Nat Nanotechnol. 2007;2(12):765-769.

23. Laudenslager MJ, Schiffman JD, Schauer CL. Carboxymethyl chitosan as a matrix material for platinum, gold, and silver nanoparticles. Biomacromolecules. 2008;9(10):2682-2585.

24. Ahmad MB, Shlameli K, Darroudi M, et al. Synthesis and Characterization of Silver/Clay/Chitosan Bionanocomposites by UVIrradiation Method. American Journal of Applied Sciences. 2009; 6(12):2030-2035.

25. Regiel A, Irusta S, Kyzioł A, Arruebo M, Santamaria J. Preparation and characterization of chitosan-silver nanocomposite films and their antibacterial activity against Staphylococcus aureus. Nanotechnology. 2013;24(1):015101.

26. Bin Ahmad M, Lim JJ, Shameli K, Ibrahim NA, Tay MY. Synthesis of silver nanoparticles in chitosan, gelatin and chitosan/gelatin bionanocomposites by a chemical reducing agent and their characterization. Molecules. 2011;16(9):7237-7248.

27. Fouda MM, El-Aassar MR, Al-Deyab SS. Antimicrobial activity of carboxymethyl chitosan/polyethylene oxide nanofibers embedded silver nanoparticles. Carbohydr Polym. 2013;92(2):1012-1017.

28. Barani H, Montazer M, Toliyat T, Samadi N. Synthesis of Ag-liposome nano composites. J Liposome Res. 2010;20(4):323-329.

29. Fortunati E, Armentano I, Zhou Q, et al. Multifunctional bionanocomposite films of poly(lactic acid), cellulose nanocrystals and silver nanoparticles. Carbohydrate Polymers. 2012;87(2):1596-1605.

30. Muzalev PA, Kosobudskii ID, Kul'batskii DM, Ushakov NM. Polymer composites based on polymethylmethacrylate with silver nanoparticles, synthesis and optical properties. Inorganic Materials: Applied Research. 2012;3(1):40-43.

31. Pencheva D, Bryaskova R, Lad U, Kale GM, Kantardjiev T. Sporocidic properties of poly(vinyl alcohol)/silver nanoparticles/TEOS thin hybrid films. J Biomed Nanotechnol. 2012;8(3):465-472.

32. Xu G, Qiao X, Qiu X, Chen J. Preparation and characterization of stable monodisperse silver nanoparticles via photoreduction. Colloids and Surfaces A: Physicochemical and Engineering Aspects. 2008;320(1-3):222-226.

33. Slistan-Grijalva A, Herrera-Urbina R, Rivas-Silva JF, et al. Synthesis of silver nanoparticles in a polyvinylpyrrolidone (PVP) paste, and their optical properties in a film and in ethylene glycol. Materials Research Bulletin. 2008;43(1):90-96.

34. Wei D, Sun W, Qian W, Ye Y, Ma X. The synthesis of chitosan-based silver nanoparticles and their antibacterial activity. Carbohydr Res. 2009;344(17):2375-2382.

35. Tran HV, Bac CT, Dinh VH, et al. Synthesis, characterization, antibacterial and antiproliferative activities of monodisperse chitosan-based silver nanoparticles. Colloids and Surfaces A: Physicochemical and Engineering Aspects. 2010;360(1-3):32-40.

36. Bankura KP, Maity D, Mollick MM, et al. Synthesis, characterization and antimicrobial activity of dextran stabilized silver nanoparticles in aqueous medium. Carbohydrate Polym. 2012;89(4):1159-1165.

37. El-Rafie HM, El-Rafie MH, Zahran MK. Green synthesis of silver nanoparticles using polysaccharides extracted from marine macro algae. Carbohydr Polym. 2013;96(2):403-410.

38. Wang CW, Tseng SJ, Peng SF, Hwu YK, Lin CK. Functionalized polymer spheres via one-step photoinduced synthesis for antimicrobial activity and gene delivery. Nanotechnology. 2012;23(25):255103.

39. Abdel-Mohsen AM, Aly AS, Hrdina R, El-Aref AT. A novel method for the preparation of silver/chitosan-O-methoxy polyethylene glycol core shell nanoparticles. Journal of Polymers and the Environment. 2011;20(2):459-468.

40. Gangadharan D, Harshvardan K, Gnanasekar G, et al. Polymeric microspheres containing silver nanoparticles as a bactericidal agent for water disinfection. Water Res. 2010;44(18):5481-5487. 
41. Huang KS, Wang CY, Yang CH, et al. Synthesis and characterization of oil-chitosan composite spheres. Molecules. 2013;18(5):5749-5760.

42. Wang C-Y, Yang C-H, Huang K-S, et al. Electrostatic droplets assisted in situ synthesis of superparamagnetic chitosan microparticles for magnetic-responsive controlled drug release and copper ion removal. Journal of Materials Chemistry B. 2013;1(16):2205.

43. Yang $\mathrm{CH}$, Wang $\mathrm{CY}$, Huang $\mathrm{KS}$, et al. Facile synthesis of radiallike macroporous superparamagnetic chitosan spheres with in-situ co-precipitation and gelation of ferro-gels. PLoS One. 2012;7(11): e49329.

44. Lin YS, Huang KS, Yang CH, et al. Microfluidic synthesis of microfibers for magnetic-responsive controlled drug release and cell culture. PLoS One. 2012;7(3): 33184.

45. Chen Z, Zhang X, Cao H, Huang Y. Chitosan-capped silver nanoparticles as a highly selective colorimetric probe for visual detection of aromatic ortho-trihydroxy phenols. Analyst. 2013;138(8):2343-2349.

46. Mejia AF, He P, Luo D, Marquez M, Cheng Z. Uniform discotic wax particles via electrospray emulsification. J Colloid Interface Sci. 2009;334(1):22-28.

47. Kandile NG, Nasr AS. Environment friendly modified chitosan hydrogels as a matrix for adsorption of metal ions, synthesis and characterization. Carbohydrate Polymers. 2009;78(4):753-759.

48. Yallapu MM, Gupta BK, Jaggi M, Chauhan SC. Fabrication of curcumin encapsulated PLGA nanoparticles for improved therapeutic effects in metastatic cancer cells. J Colloid Interface Sci. 2010;351(1):19-29.

49. Vimala K, Mohan YM, Sivudu KS, et al. Fabrication of porous chitosan films impregnated with silver nanoparticles: a facile approach for superior antibacterial application. Colloids Surf B Biointerfaces. 2010;76(1):248-258.

50. www.sigmaaldrich.com [homepage on the Internet]. Oldenburg SJ. Silver Nanoparticles: Properties and Applications. Sigma-Aldrich Co; 2013. Available from: http://www.sigmaaldrich.com/materials-science/ nanomaterials/silver-nanoparticles.html\#optical. Accessed January 15, 2015.

51. Mukherjee P, Ahmad A, Mandal D, et al. Fungus-Mediated Synthesis of Silver Nanoparticles and Their Immobilization in the Mycelial Matrix: A Novel Biological Approach to Nanoparticle Synthesis. Nano Letters. 2001;1(10):515-519.

52. Mubarak Ali D, Sasikala M, Gunasekaran M, Thajuddin N. Biosynthesis and characterization of silver nanoparticles using marine cyanobacterium, oscillatoria willei NTDM01. Digest Journal of Nanomaterials and Biostructures. 2011;5(2):385-390.

53. Stebounova LV, Adamcakova-Dodd A, Kim JS, et al. Nanosilver induces minimal lung toxicity or inflammation in a subacute murine inhalation model. Part Fibre Toxicol. 2011;8(1):5.

54. Lu LC, Wang CI, Sye WF. Applications of chitosan beads and porous crab shell powder for the removal of 17 organochlorine pesticides (OCPs) in water solution. Carbohydrate Polymers. 2011;83(4):1984-1989.
55. Tran HV, Tran LD, Nguyen TN. Preparation of chitosan/magnetite composite beads and their application for removal of $\mathrm{Pb}(\mathrm{II})$ and $\mathrm{Ni}(\mathrm{II})$ from aqueous solution. Materials Science and Engineering: $C$. 2010;30(2):304-310.

56. Chen X, Schluesener HJ. Nanosilver: A nanoproduct in medical application. Toxicol Lett. 2008;176(1):1-12.

57. Poon VK, Burd A. In vitro cytotoxity of silver: implication for clinical wound care. Burns. 2004;30(2):140-147.

58. Rai M, Yadav A, Gade A. Silver nanoparticles as a new generation of antimicrobials. Biotechnol Adv. 2009;27(1):76-83.

59. Moritz M, Geszke-Moritz M. The newest achievements in synthesis, immobilization and practical applications of antibacterial nanoparticles. Chemical Engineering Journal. 2013;228:596-613.

60. Abbasi AR, Akhbari K, Morsali A. Dense coating of surface mounted CuBTC Metal-Organic Framework nanostructures on silk fibers, prepared by layer-by-layer method under ultrasound irradiation with antibacterial activity. Ultrason Sonochem. 2012;19(4):846-852.

61. Montazer M, Shamei A, Alimohammadi F. Stabilized nanosilver loaded nylon knitted fabric using BTCA without yellowing. Progress in Organic Coatings. 2012;74(1):270-276.

62. Pinto RJ, Fernandes SC, Freire CS, et al. Antibacterial activity of optically transparent nanocomposite films based on chitosan or its derivatives and silver nanoparticles. Carbohydrate Research. 2012;348:77-83.

63. Jena P, Mohanty S, Mallick R, Jacob B, Sonawane A. Toxicity and antibacterial assessment of chitosan-coated silver nanoparticles on human pathogens and macrophage cells. Int J Nanomedicine. 2012;7:1805-1818.

64. Rai MK, Deshmukh SD, Ingle AP, Gade AK. Silver nanoparticles: the powerful nanoweapon against multidrug-resistant bacteria. $J$ Appl Microbiol. 2012;112(5):841-852.

65. Morones JR, Elechiguerra JL, Camacho A, et al. The bactericidal effect of silver nanoparticles. Nanotechnology. 2005;16(10):2346-2353.

66. Yoksan R, Chirachanchai S. Silver nanoparticles dispersing in chitosan solution: Preparation by $\gamma$-ray irradiation and their antimicrobial activities. Materials Chemistry and Physics. 2009;115(1):296-302.

67. Lopez-Carballo G, Higueras L, Gavara R, Hernández-Muñoz P. Silver ions release from antibacterial chitosan films containing in situ generated silver nanoparticles. J Agric Food Chem. 2013;61(1):260-267.

68. Youssef AM, Abdel-Aziz MS, El-Sayed SM. Chitosan nanocomposite films based on Ag-NP and Au-NP biosynthesis by Bacillus Subtilis as packaging materials. Int J Biol Macromol. 2014;69:185-191.

69. Mohamed RR, Sabaa MW. Synthesis and characterization of antimicrobial crosslinked carboxymethyl chitosan nanoparticles loaded with silver. Int J Biol Macromol. 2014;69:95-99. 


\section{Supplementary materials}

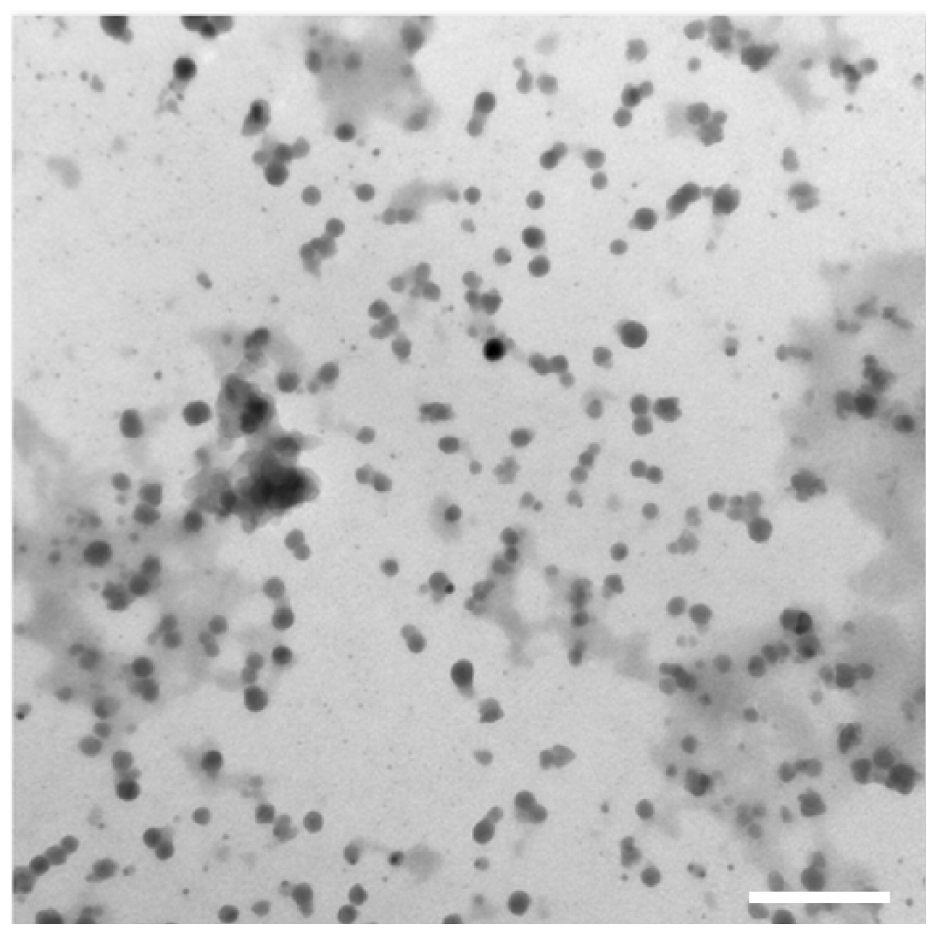

Figure SI The transmission electron microscopy photograph of the synthesized silver nanoparticles.

Notes: The silver nanoparticles-chitosan composite sphere was granulated, uniformly dispersed in water. The scale bar is $100 \mathrm{~nm}$.
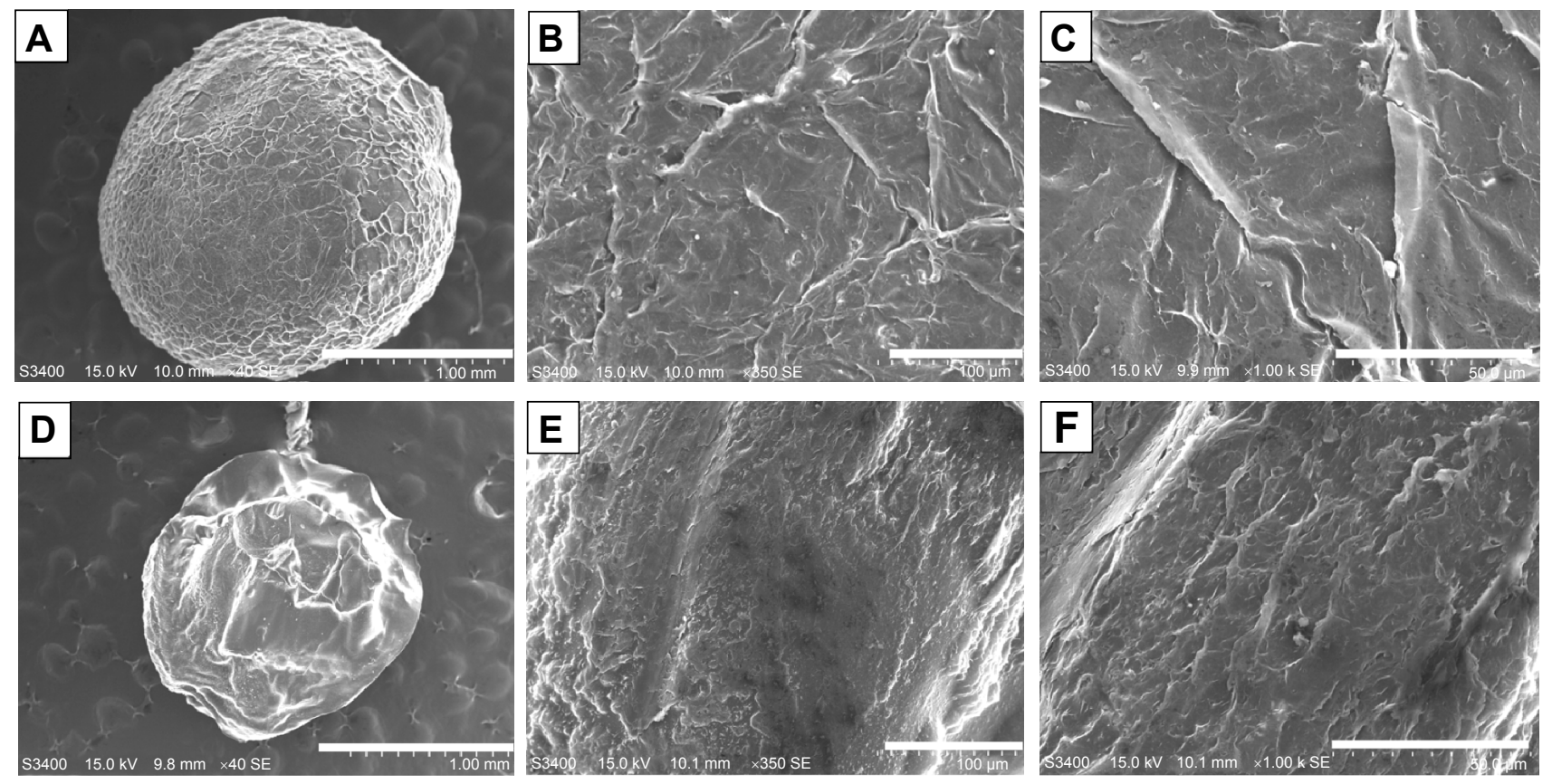

Figure S2 The transmission electron microscopy (SEM) photographs of the synthesized chitosan spheres.

Notes: Panel (A) is an SEM photograph of a whole chitosan sphere. Panels (B) and (C) are the "zoom-in" counterparts of (A). Panel (D) is an SEM photograph of a sectioned chitosan sphere. Panels $(\mathbf{E})$ and $(\mathbf{F})$ are the "zoom-in" counterparts of $(\mathbf{D})$. The scale bars are I mm for $(\mathbf{A})$ and $(\mathbf{D}), 100 \mu \mathrm{m}$ for $(\mathbf{B})$ and $(\mathbf{E})$, and $50 \mu \mathrm{m}$ for $(\mathbf{C})$ and $(\mathbf{F})$, respectively. 

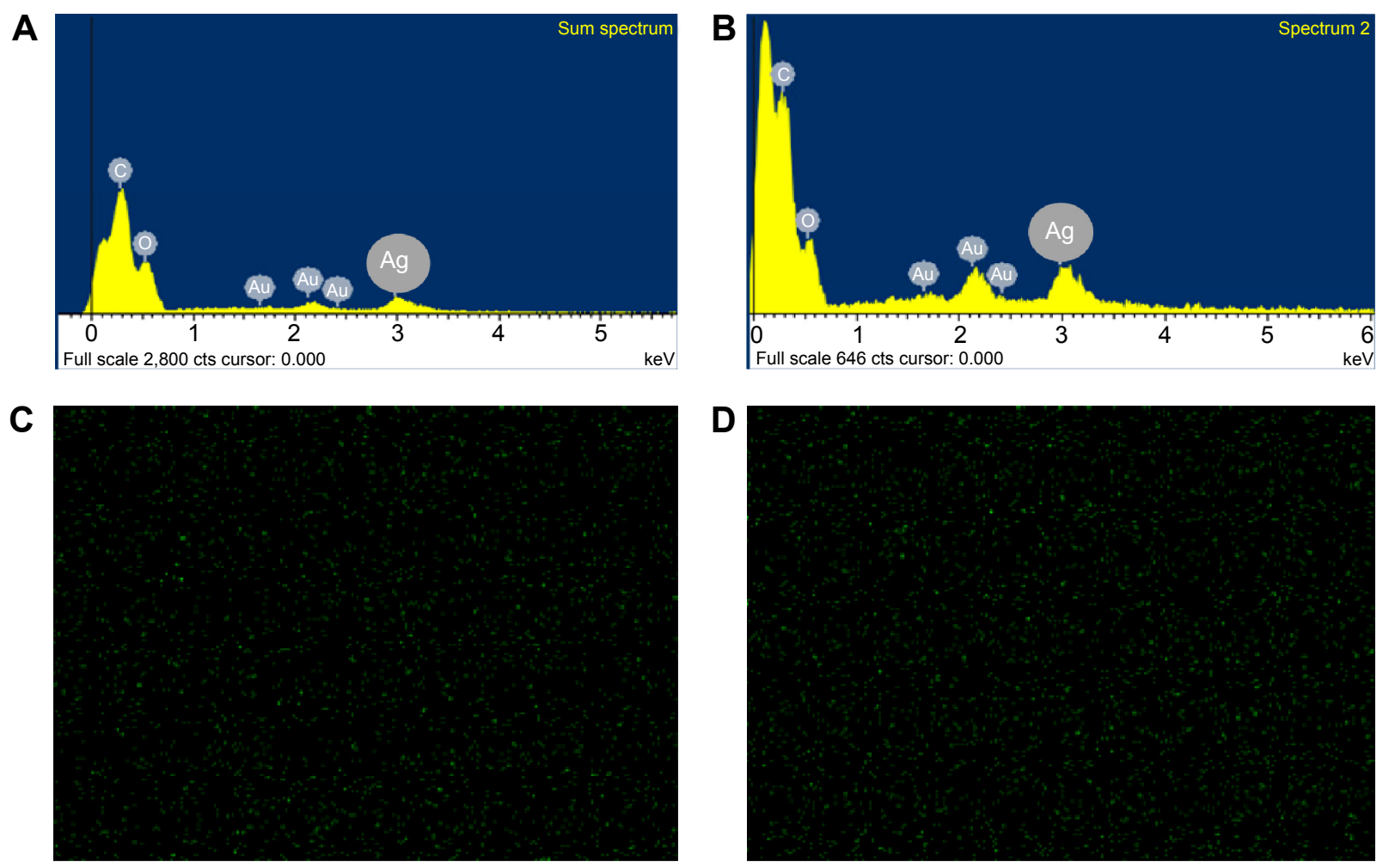

Figure S3 The SEM-EDS mappings of silver nanoparticles deposited on the outer surface (A, C) and inside (B, D) of the synthesized silver nanoparticles-chitosan composite sphere.

Abbreviation: SEM-EDS, scanning electron microscopy-energy dispersive spectroscopy.

\section{Publish your work in this journal}

The International Journal of Nanomedicine is an international, peerreviewed journal focusing on the application of nanotechnology in diagnostics, therapeutics, and drug delivery systems throughout the biomedical field. This journal is indexed on PubMed Central, MedLine, CAS, SciSearch $®$, Current Contents ${ }^{\circledR} /$ Clinical Medicine,
Journal Citation Reports/Science Edition, EMBase, Scopus and the Elsevier Bibliographic databases. The manuscript management system is completely online and includes a very quick and fair peer-review system, which is all easy to use. Visit http://www.dovepress.com/ testimonials.php to read real quotes from published authors. 